\title{
A combined fractional flow reserve and optical coherence tomography approach to guide coronary artery bypass grafting: A pilot study
}

Francesco Fracassi, MD, ${ }^{\text {a }}$ Tomoyo Sugiyama, MD, PhD, ${ }^{\text {a }}$ Erika Yamamoto, $\mathrm{MD}, \mathrm{PhD},{ }^{\mathrm{a}}$

Brian Ghoshhajra, MD, ${ }^{\mathrm{b}}$ Amy Gin, MD, ${ }^{\mathrm{a}}$ Mazen Albaghdadi, MD, ${ }^{\mathrm{a}}$ Hang Lee, $\mathrm{PhD}$,

Serguei Melnitchouk, MD, ${ }^{\mathrm{d}}$ Thoralf Mauritz Sundt, MD, ${ }^{\mathrm{d}}$ and Ik-Kyung Jang, MD, PhD, ${ }^{a}$ Boston, Mass

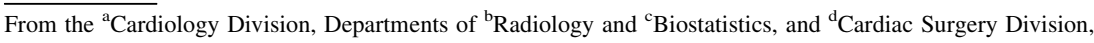
Massachusetts General Hospital, Harvard Medical School, Boston, Mass.

This study was funded by a Massachusetts General Hospital Spark Grant.

Disclosures: Authors have nothing to disclose with regard to commercial support.

Received for publication March 2, 2018; revisions received April 20, 2018; accepted for publication May 7, 2018; available ahead of print June 28, 2018.

Address for reprints: Ik-Kyung Jang, MD, PhD, Cardiology Division, Massachusetts General Hospital, 55 Fruit

St, GRB 800, Boston, MA 02114 (E-mail: ijang@mgh.harvard.org).

J Thorac Cardiovasc Surg 2018;156:997-1000

$0022-5223 / \$ 36.00$

Copyright (C) 2018 by The American Association for Thoracic Surgery

https://doi.org/10.1016/j.jtcvs.2018.05.037

Coronary artery bypass grafting (CABG) is a wellestablished treatment for multivessel coronary disease. Nonculprit lesion severity is usually evaluated angiographically, without considering physiology; this may affect graft outcome. Two factors are considered important for long-term graft patency in addition to surgical aspects: functional significance of the target lesion ${ }^{1,2}$ and plaque

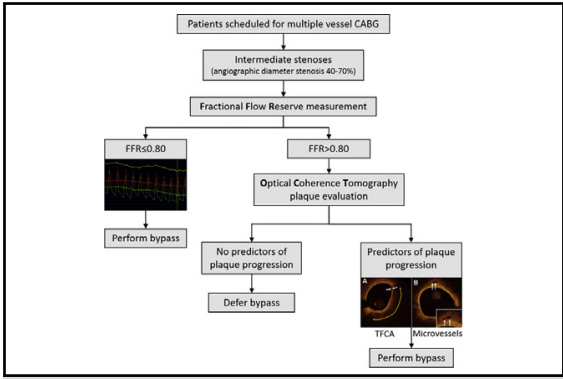

Novel approach for the management of multivessel disease in patients scheduled to $\mathrm{CABG}$.

Central Message

This prospective proof-of-concept study proposes an integration of fractional flow reserve and optical coherence tomography to predict bypass graft outcome.

See Editorial Commentary page 1001 morphology. ${ }^{3}$ A previous optical coherence tomography
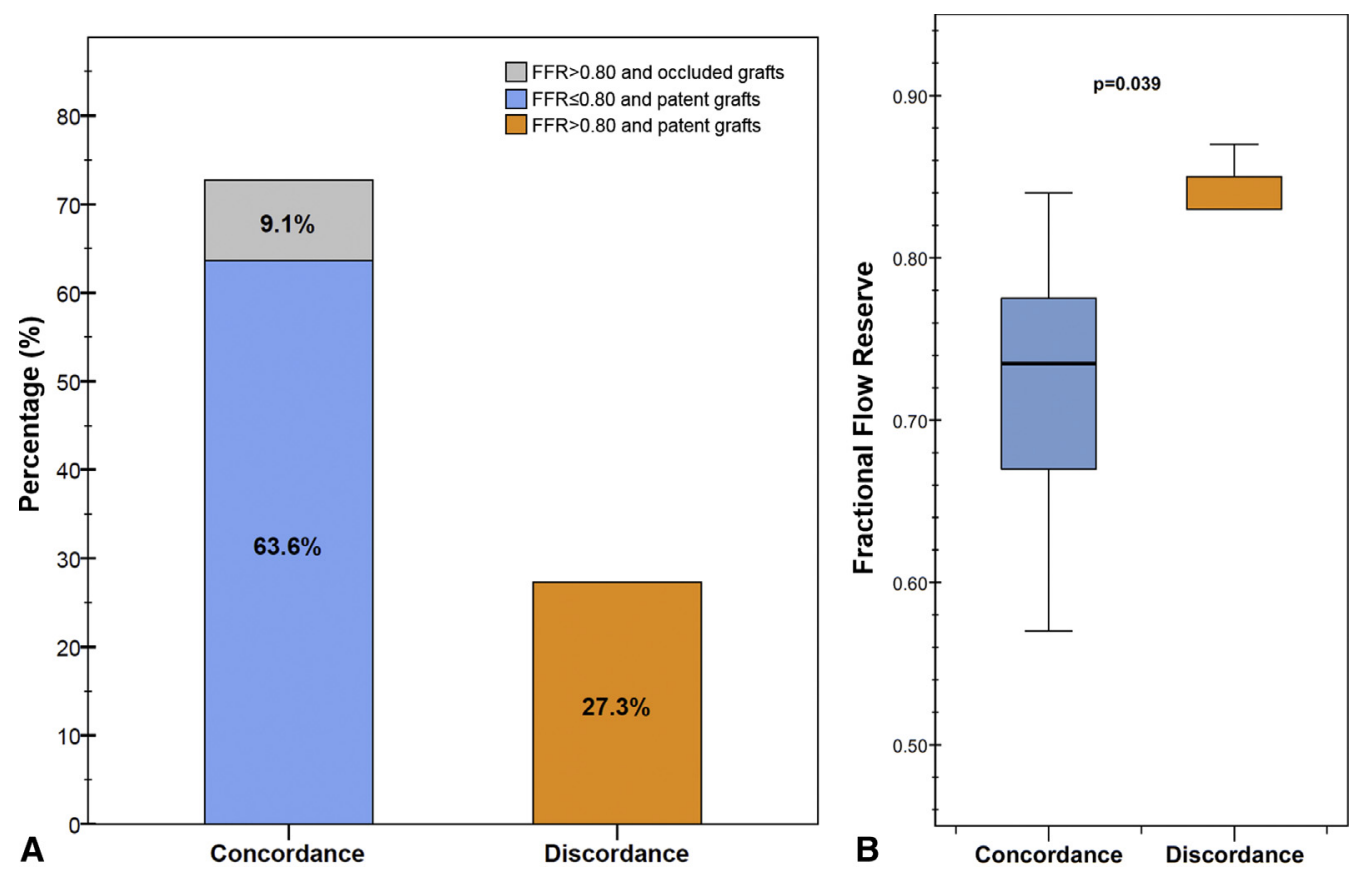

FIGURE 1. A, Rates of concordant and discordant lesions according to baseline functional stenosis severity and bypass graft patency at follow-up. B, Fractional flow reserve $(F F R)$ values for concordant and discordant lesions. 
(OCT) study showed that thin-cap fibroatheroma (TCFA) and microvessels predict rapid plaque progression. ${ }^{4}$ In this pilot study, we sought to predict grafts patency at follow-up by using pre-CABG fractional flow reserve (FFR) and OCT studies.

\section{MATERIALS AND METHODS}

This prospective study included candidates for CABG with at least 1 angiographic intermediate lesion (40\%-70\%). All intermediate stenoses were interrogated by FFR and then with OCT when the FFR value was greater than 0.80 . At 10 months, computed tomographic angiography was performed to evaluate graft patency. To test our hypothesis, we defined lesions with positive FFR results and patent graft or negative FFR results and occluded graft as "concordant" and lesions with negative FFR results and patent graft or positive FFR results and occluded graft as "discordant." Similarly, in the OCT subgroup analysis, lesions with OCT characteristics of plaque progression (TCFA or microvessels) and patent graft or OCT characteristics of stable plaque and occluded graft were defined as "concordant" and lesions with OCT characteristics of plaque progression and occluded graft or OCT characteristics of stable plaque and patent graft as "discordant."

Continuous variables were compared with the unpaired Student $t$ test, and data are expressed as mean \pm SD. Categoric data were evaluated with the Fisher exact test. All tests were 2-sided and performed with SPSS 23.0 (IBM, Armonk, NY). All patients provided written consent before enrollment.

TABLE 1. Angiographic, functional, and morphologic characteristics of lesions according to concordance between fractional flow reserve or optical coherence tomography findings and bypass graft patency at follow-up

\begin{tabular}{|c|c|c|c|c|}
\hline & Overall lesions & Concordant lesions & Discordant lesions & $P$ value \\
\hline \multicolumn{5}{|l|}{ FFR study of all lesions } \\
\hline Total lesions & 11 & $8(72.7 \%)$ & $3(27.3 \%)$ & \\
\hline Diagnosis & & & & .491 \\
\hline Stable angina & $7(63.6 \%)$ & $6(75.0 \%)$ & $1(33.3 \%)$ & \\
\hline NSTE-ACS & $4(36.4 \%)$ & $2(25.0 \%)$ & $2(66.7 \%)$ & \\
\hline Vessel & & & & .03 \\
\hline Right coronary artery & $4(36.4 \%)$ & $1(12.5 \%)$ & $3(100 \%)$ & \\
\hline Left anterior descending artery & $3(27.3 \%)$ & $3(37.5 \%)$ & $0(0 \%)$ & \\
\hline Left circumflex artery & $4(36.4 \%)$ & $4(50.0 \%)$ & $0(0 \%)$ & \\
\hline Type of graft conduit & & & & .236 \\
\hline Arterial & $4(36.4 \%)$ & $4(50 \%)$ & $0(0 \%)$ & \\
\hline Venous & $7(63.6 \%)$ & $4(50 \%)$ & $3(100 \%)$ & \\
\hline \multicolumn{5}{|l|}{ Quantitative coronary angiography } \\
\hline Reference vessel diameter (mm) & $2.8 \pm 0.4$ & $2.7 \pm 0.4$ & $2.8 \pm 0.4$ & .69 \\
\hline Minimum lumen diameter (mm) & $1.1 \pm 0.3$ & $1.1 \pm 0.3$ & $1.2 \pm 0.2$ & .76 \\
\hline Lesion length $(\mathrm{mm})$ & $17.1 \pm 3.6$ & $17.0 \pm 3.9$ & $17.6 \pm 3.3$ & .82 \\
\hline DS $(\%)$ & $59.3 \pm 7.2$ & $59.4 \pm 8.4$ & $59.0 \pm 3.6$ & .94 \\
\hline \multicolumn{5}{|l|}{ Functional assessment } \\
\hline FFR & $0.76 \pm 0.09$ & $0.72 \pm 0.08$ & $0.84 \pm 0.02$ & .039 \\
\hline FFR evaluation & & & & .024 \\
\hline Negative FFR & $4(36.4 \%)$ & $1(12.5 \%)$ & $3(100 \%)$ & \\
\hline Positive FFR & $7(63.6 \%)$ & $7(87.5 \%)$ & $0(0 \%)$ & \\
\hline Time to CTA (mo) & $10.6 \pm 3.4$ & $11.5 \pm 3.2$ & $8.3 \pm 3.2$ & .18 \\
\hline \multicolumn{5}{|l|}{$\begin{array}{l}\text { OCT assessment of FFR-negative } \\
\text { lesions }\end{array}$} \\
\hline $\begin{array}{l}\text { No. of FFR-negative lesions } \\
\text { studied }\end{array}$ & 4 & $2(50 \%)$ & $2(50 \%)$ & \\
\hline \multicolumn{5}{|l|}{ Quantitative assessment } \\
\hline Minimum lumen area, mm & $2.43 \pm 0.78$ & $2.39 \pm 0.35$ & $2.48 \pm 0.36$ & .93 \\
\hline Lesion length, mm & $18.5 \pm 2.6$ & $16.3 \pm 0.8$ & $20.7 \pm 0.9$ & .032 \\
\hline Fibrous cap thickness, $\mu \mathrm{m}$ & 60.00 & - & 60.00 & - \\
\hline \multicolumn{5}{|l|}{ Qualitative assessment } \\
\hline Lipid plaque & $1(25 \%)$ & $0(0 \%)$ & $1(50 \%)$ & $>.999$ \\
\hline Thin-cap fibroatheroma & $1(25 \%)$ & $0(0 \%)$ & $1(50 \%)$ & $>.999$ \\
\hline Fibrous plaque & $3(75 \%)$ & $2(100 \%)$ & $1(50 \%)$ & $>.999$ \\
\hline Calcifications & $2(50 \%)$ & $0(0 \%)$ & $2(100 \%)$ & .33 \\
\hline Macrophages infiltration & $3(75 \%)$ & $2(100 \%)$ & $1(50 \%)$ & $>.999$ \\
\hline Microvessels & $2(50 \%)$ & $1(50 \%)$ & $1(50 \%)$ & $>.999$ \\
\hline
\end{tabular}

Values are mean $\pm \mathrm{SD}$ or $\mathrm{n}(\%) . F F R$, Fractional flow reserve; $N S T E-A C S$, non-ST-elevation acute coronary syndrome; $D S$, diameter stenosis; $C T A$, computed tomography angiography; $O C T$, optical coherence tomography. 


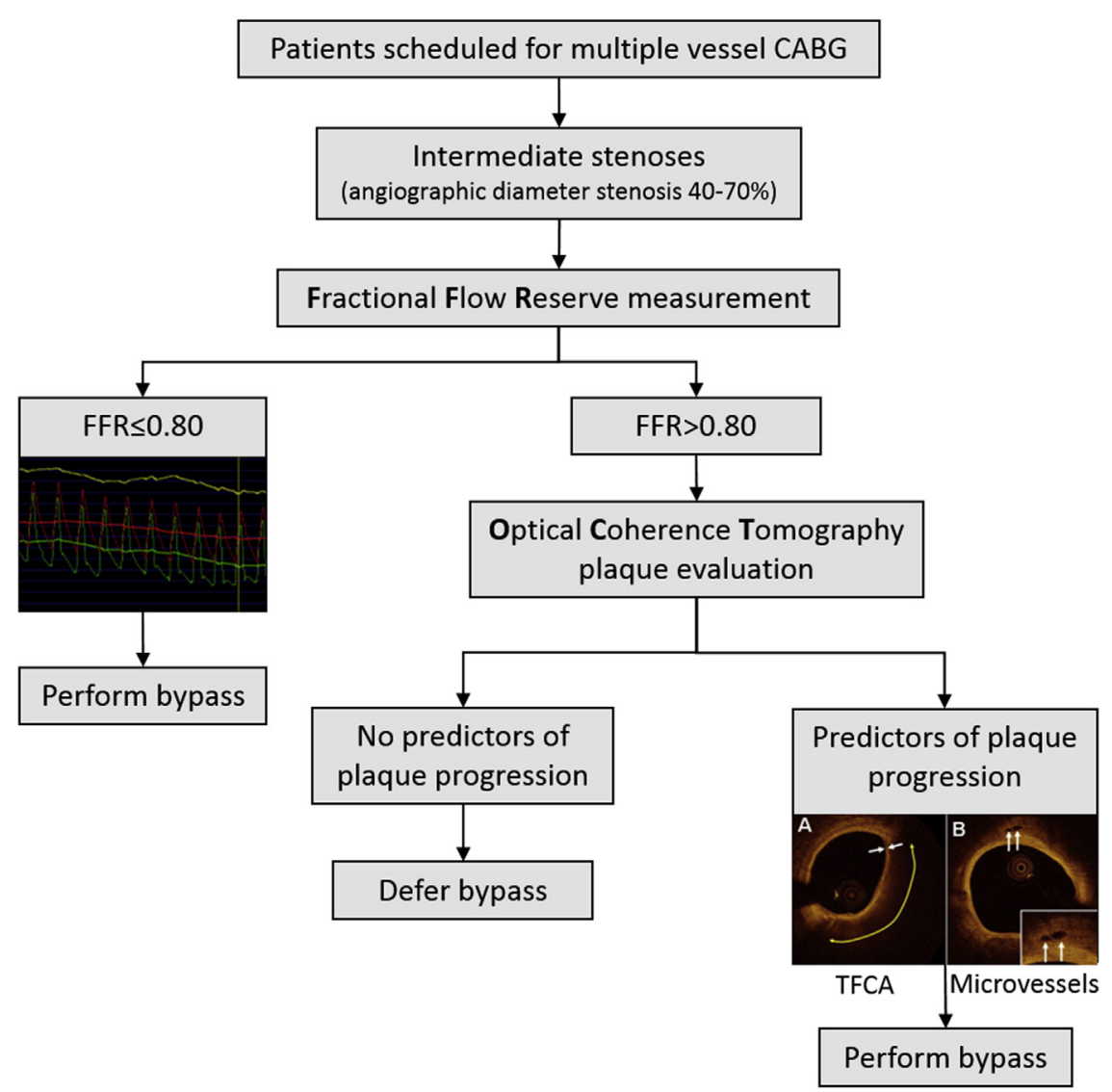

FIGURE 2. Novel approach for the management of angiographically intermediate stenoses in patients with multivessel disease who are scheduled to undergo coronary artery bypass surgery $(C A B G)$. The first step consists of fractional flow reserve $(F F R)$ evaluation of the functional significance of intermediate lesions. In the presence of critical stenosis (fractional flow reserve value $<0.80$ ), bypass should be performed. In the case of a negative fractional flow reserve result (fractional flow reserve value $>0.80$ ), optical coherence tomography $(\mathrm{OCT})$ is proposed. If an OCT predictor of rapid plaque progression (thin-cap fibroatheroma $[T C F A]$ or microvessels) is present, revascularization of the lesion should be considered. OCT images in the right lower corner show the predictors of rapid plaque progression: thin-cap fibroatheroma $(A)$, characterized by thin fibrous cap (white arrows) and large lipid pool (yellow line), and microvessels $(B)$, signal-poor circular structures in a plaque with a diameter less than $250 \mu \mathrm{m}$ (white arrows).

\section{RESULTS}

This pilot study enrolled 9 male patients $(61.4 \pm 9.4$ years of age), 5 with stable angina and 4 with non-ST-elevation acute coronary syndrome. Out of 12 intermediate lesions evaluated with FFR, 5 lesions $(41.7 \%)$ had negative FFR results. Because 1 patient reported contrast allergy, $4(33.3 \%)$ lesions were assessed by OCT. Computed tomographic angiography was performed at $10.6 \pm 3.4$ months. Eleven lesions $(91.2 \%)$ were included in the final analysis. FFR concordance was found for 8 lesions $(72.7 \%$; Figure $1, A)$. Among the graft conduits, 4 were arterial and 7 were venous, with no significant difference according to FFR concordance. Of note, FFR discordance was recorded for 3 venous grafts, all of which were placed in the right coronary artery. FFR values were significantly lower, and positive FFR results were more frequent in concordant lesions than in discordant ones $(0.72 \pm 0.08$ vs $0.84 \pm 0.02 ; P=.039$; Figure $1, B$; and $7[87.5 \%]$ vs $0[0 \%] ; P=.024$, respectively). OCT concordance was found for 2 lesions $(50 \%)$. No significant differences in OCT characteristics were found between the 2 groups, other than longer lesion length in the discordant group $(20.70 \pm 0.85 \mathrm{~mm}$ vs $16.25 \pm 0.78 \mathrm{~mm} ; P=.032)$. Data are reported in Table 1.

\section{DISCUSSION}

In current practice, functional assessment is rarely used in the decision-making process for patients who are candidates for CABG. Botman and colleagues, ${ }^{2}$ however, found a higher 1-year patency rate when a graft was placed for a functionally significant stenosis in 164 patients. Our report confirms these results, supporting the well-known theory that competitive flow resulting from nonsignificant lesions may lead to graft failure. ${ }^{5}$ We indeed observed a higher 
prevalence of concordance between functional severity of the lesion and graft patency at follow-up. Moreover, we found that negative FFR values had a significantly lower predictive value for concordance, suggesting that outcome of grafts bypassing lesions with negative FFR cannot be predicted by baseline FFR alone. There are 2 patterns of plaque progression: slow linear progression and rapid phasic progression. ${ }^{6}$ The latter is probably related to plaque destabilization or intraplaque hemorrhage. Rapid plaque progression (6 months) may be predicted by OCT demonstration of TCFA and microchannels. ${ }^{3}$ Xie and associates ${ }^{4}$ found that a quarter of coronary plaques progressed during a 12-month period; among these, two-thirds of the lesions presented a rapid phasic progression pattern; and TCFA and microvessels were independent predictors of rapid phasic progression. On these bases, we propose to assess intermediate stenoses with OCT either to predict the need of short-term revascularization in the presence of predictors of rapid plaque progression or to improve the negative predictive value of negative FFR results (Figure 2). We observed, however, an equal distribution of OCT concordance and discordance. In addition, because lesions with OCT concordance were longer, the ability of OCT to predict progression of complex lesions seems lower. Because of the small number of subjects, no meaningful conclusion can be drawn regarding the role of OCT in predicting graft outcome. This approach, combining physiology and biology, warrants further investigation in larger studies. It may also be implemented by intraoperative graft flow assessment, which could identify potential technical issues occurring during $\mathrm{CABG}$.

\section{References}

1. Toth G, De Bruyne B, Casselman F, De Vroey F, Pyxaras S, Di Serafino L, et al. Fractional flow reserve-guided versus angiography-guided coronary artery bypass graft surgery. Circulation. 2013;128:1405-11.

2. Botman CJ, Schonberger J, Koolen S, Penn O, Botman H, Dib N, et al. Does stenosis severity of native vessels influence bypass graft patency? A prospective fractional flow reserve-guided study. Ann Thorac Surg. 2007; 83:2093-7.

3. Uemura S, Ishigami K, Soeda T, Okayama S, Sung JH, Nakagawa H, et al. Thincap fibroatheroma and microchannel findings in optical coherence tomography correlate with subsequent progression of coronary atheromatous plaques. Eur Heart J. 2012;33:78-85.

4. Xie Z, Hou J, Yu H, Jia H, Du H, Lee H, et al. Patterns of coronary plaque progression: phasic versus gradual. A combined optical coherence tomography and intravascular ultrasound study. Coron Artery Dis. 2016;27:658-66.

5. Paterson HS, Bannon PG, Taggart DP. Competitive flow in coronary bypass surgery: the roles of fractional flow reserve and arterial graft configuration. $J$ Thorac Cardiovasc Surg. 2017; 154:1570-5.

6. Jang IK. Plaque progression: slow linear or rapid stepwise? Circ Cardiovasc Imaging. 2017;10. 